OPEN ACCESS

Edited by:

Dongsheng Zhou,

Beijing Institute of Microbiology and Epidemiology, China

Reviewed by:

Boris Görke

University of Vienna, Austria Johannes Geiselmann, Joseph Fourier University, France

${ }^{*}$ Correspondence:

Stuart B. Levy stuart.levy@tufts.edu

Valérie Duval

valerie.duval@tufts.edu

Specialty section:

This article was submitted to Microbial Physiology and Metabolism, a section of the journal

Frontiers in Microbiology

Received: 16 February 2017 Accepted: 07 June 2017

Published: 30 June 2017

Citation:

Duval V, Foster K, Brewster J and Levy SB (2017) A Novel Regulatory Cascade Involving BluR, YcgZ, and Lon Controls the Expression of Escherichia coli OmpF Porin.

Front. Microbiol. 8:1148. doi: 10.3389/fmicb.2017.01148

\section{A Novel Regulatory Cascade Involving BluR, YcgZ, and Lon Controls the Expression of Escherichia coli OmpF Porin}

\author{
Valérie Duval*, Kimberly Foster, Jennifer Brewster and Stuart B. Levy* \\ Center for Adaptation Genetics and Drug Resistance, Department of Molecular Biology and Microbiology, Tufts University \\ School of Medicine, Boston, MA, United States
}

In Escherichia coli, OmpF is an important outer membrane protein, which serves as a passive diffusion pore for small compounds including nutrients, antibiotics, and toxic compounds. OmpF expression responds to environmental changes such as temperature, osmolarity, nutrients availability, and toxic compounds via complex regulatory pathways involving transcriptional and post-transcriptional regulation. Our study identified a new regulatory cascade that controls the expression of OmpF porin. This pathway involves BluR, a transcriptional regulator repressing the expression of the $y c g Z$-ymgABC operon. We showed that BluR was responsible for the temperaturedependent regulation of the $y c g Z-y m g A B C$ operon. Furthermore, our results showed that independent expression of $Y c g Z$ led to a decreased activity of the ompF promoter, while YmgA, YmgB, and YmgC expression had no effect. We also determined that YcgZ accumulates in the absence of the Lon protease. Thus, mutation in bluR leads to derepression of $y c g Z-y m g A B C$ transcription. With a second mutation in lon, YcgZ protein accumulates to reach levels that do not allow increased expression of OmpF under growth conditions that usually would, i.e., low temperature. With BluR responding to blue-light and temperature, this study sheds a new light on novel signals able to regulate OmpF porin.

\section{Keywords: regulation, porin, Lon protease, E. coli, blue light, temperature}

\section{INTRODUCTION}

The outer membrane of Gram-negative bacteria provides a physical barrier to hydrophobic and hydrophilic compounds including many toxic molecules (Pagès et al., 2008). Embedded in the outer membrane, the porins (outer membrane proteins or OMPs) have multiple functions: allowing the diffusion of small molecules, stabilizing the cell envelope, and acting as receptors for phages and bacteriocins or as virulence factors in pathogenic bacteria (Achouak et al., 2001; Nikaido, 2003; Galdiero et al., 2012). Three major porins are found in abundance in the outer membrane of Escherichia coli: OmpA, OmpC, and OmpF (Achouak et al., 2001). With only a small fraction of the porin forming open channels, OmpA seems to be mainly involved in maintaining the shape of the cell (Sugawara and Nikaido, 1994). Conversely, OmpF and OmpC form hydrophilic pores that allow the diffusion of small nutrients and toxic compounds (Chopra and Eccles, 1978; Yoshimura and Nikaido, 1985; Mortimer and Piddock, 1993; Nikaido, 1994, 2003). Although OmpF and 
OmpC display a similar structure, each porin harbors a unique electrostatic pore potential and consequently a distinct specificity and flow rates for solutes (Cowan et al., 1995; Basle et al., 2003). In this context, OmpF plays a crucial role in the accumulation of small hydrophilic antibiotics such as monoanionic cephalosporins, tetracyclines, and fluoroquinolones (Yoshimura and Nikaido, 1985; Cohen et al., 1989; Mortimer and Piddock, 1993; Duval et al., 2009). In order to respond to changes in environmental conditions, E. coli adjusts $\mathrm{OmpF}$ and $\mathrm{OmpC}$ expression through a complex regulatory network utilizing both transcriptional and translational regulation (for review, see Forst and Inouye, 1988; Pratt et al., 1996; Vogel and Papenfort, 2006). For instance, the osmolaritydependent transcriptional control of $o m p F$ and $o m p C$ is exerted via the EnvZ/OmpR two-component signal transduction system in which EnvZ, an inner membrane histidine protein kinase, senses osmotic signals and transmits them to the transcription factor OmpR (Igo et al., 1989; Egger and Inouye, 1997; Yoshida et al., 2006). High osmolarity leads to lower OmpF levels, while relative expression of $\mathrm{OmpC}$ is increased (Forst and Inouye, 1988; Mizuno and Mizushima, 1990; Pratt et al., 1996). In addition, expression of $\mathrm{OmpF}$ and $\mathrm{OmpC}$ is controlled at the post-transcriptional level by non-translated small RNAs such as MicF, MicC, and RybB (Mizuno et al., 1984; Chen et al., 2004; Gogol et al., 2011).

A major environmental parameter that affects $\mathrm{OmpF}$ porin expression is temperature. OmpF is abundant in E. coli outer membrane at ambient temperature, while growth at $37^{\circ} \mathrm{C}$ leads to decreased amount of OmpF. It is assumed that the downregulation of $\mathrm{OmpF}$ at body temperature limits the entry of toxic bile salts into the periplasm while the bacterium is in the host's intestine (Pratt et al., 1996; Nikaido, 2003). In a previous study, we showed that mutation in two genes, lon and bluR ( $y c g E)$, prevented the upregulation of OmpF in E. coli $\mathrm{K}$ 12 grown at ambient temperature (Duval et al., 2009). BluR, a regulator harboring a MerR-like N-terminal domain, has been shown to directly repress the transcription of the adjacent $y c g Z$ $y m g A B C$ operon (ZABC operon, Figure 1; Tschowri et al., 2009). The lon locus encodes the Lon protease, an ATP-dependent serine protease involved in the degradation of unstable and misfolded proteins (Tsilibaris et al., 2006; Van Melderen and Aertsen, 2009). Lon also plays a major role in regulating multiple biological processes by controlling the abundance of specific regulatory proteins such as MarA, RcsA, and SulA (Mizusawa and
Gottesman, 1983; Torres-Cabassa and Gottesman, 1987; Griffith et al., 2004). With no available studies describing the regulation of OmpF by BluR and Lon, we investigated how BluR and Lon together control the abundance of the OmpF porin. Our study identified the $Z A B C$ operon as an intermediate in the regulation of OmpF by BluR and Lon. Precisely, we identified YcgZ as a novel repressor of $o m p F$ expression. Using a transcriptional fusion of the $o m p F$ promoter with lacZ (PompF-lacZ), we showed that YcgZ acted on ompF promoter. Finally, our study showed that the amount of YcgZ, when expressed from a plasmid, was amplified and highly stable in a lon mutant of E. coli, identifying YcgZ as a novel substrate of the Lon protease.

\section{MATERIALS AND METHODS}

\section{Bacterial Strains and Growth Conditions}

The bacterial strains used in this study are listed in Table $\mathbf{1}$. E. coli strains were cultured under agitation in LB medium (tryptone $10 \mathrm{~g} \mathrm{l}^{-1}$, yeast extract $5 \mathrm{~g} \mathrm{l}^{-1}, \mathrm{NaCl} 5 \mathrm{~g} \mathrm{l}^{-1}$ ). The same medium containing $1.5 \%$ agar was used for growing bacteria on plates. Selection of $E$. coli after transformation with pBAD and pMPM vectors was performed using ampicillin $100 \mu \mathrm{g} \mathrm{ml}^{-1}$ and tetracycline $15 \mu \mathrm{g} \mathrm{ml}^{-1}$, respectively. Kanamycin $25 \mu \mathrm{g} \mathrm{ml}^{-1}$ and chloramphenicol $12 \mu \mathrm{g} \mathrm{ml} \mathrm{m}^{-1}$ was used for selection of chromosomal insertion of kan and cat genes.

\section{Plasmids}

Expression plasmids used in this study are listed in Table $\mathbf{1}$ and were constructed as follows. The nucleotide sequence of $y c g Z, y m g A, y m g B$, and $y m g C$ was amplified by polymerase chain reaction (PCR) using the primers listed in Supplementary Table S1 and E. coli AG100 genomic DNA as template. The fragments were cloned into the $\mathrm{pBAD} / \mathrm{His}$ a and $\mathrm{pMPM}$ vectors using restriction sites indicated in Table 1 . We constructed the pDVMBluR by PCR amplification of bluR nucleotide sequence, the 200 bases upstream of start codon GTG, and the 100 bases downstream of its stop codon TAA using the primers listed in Supplementary Table S1. The PCR fragment was then ligated into the pMPM plasmid using the restriction sites EcoRI and XhoI, resulting in plasmid pDVMBluR. All nucleotide sequences were verified at the Tufts University Core Facility (Tufts University School of Medicine, Boston, MA, United States).

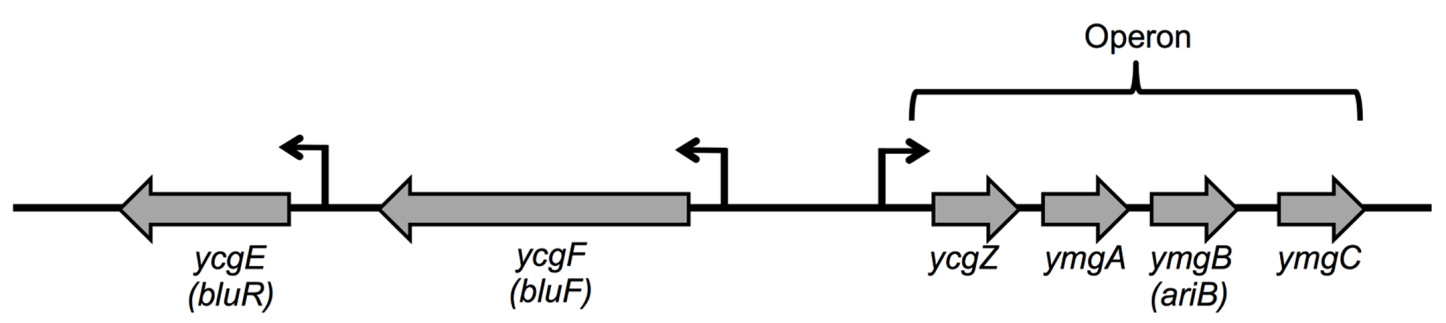

FIGURE 1 | Organization of $y c g Z-y m g A B C, y c g E$, and $y c g F$ ORFs in Escherichia coli. The bent arrows indicate the transcription start for each gene. $y c g Z$, ymgA, $y m g B$, and $y m g C$ genes are expressed as one transcript. $y c g E, y c g F$, and $y m g B$ have been renamed bluR, bluF, and ariB, respectively. 
TABLE 1 | Bacterial strains and plasmids used in this study.

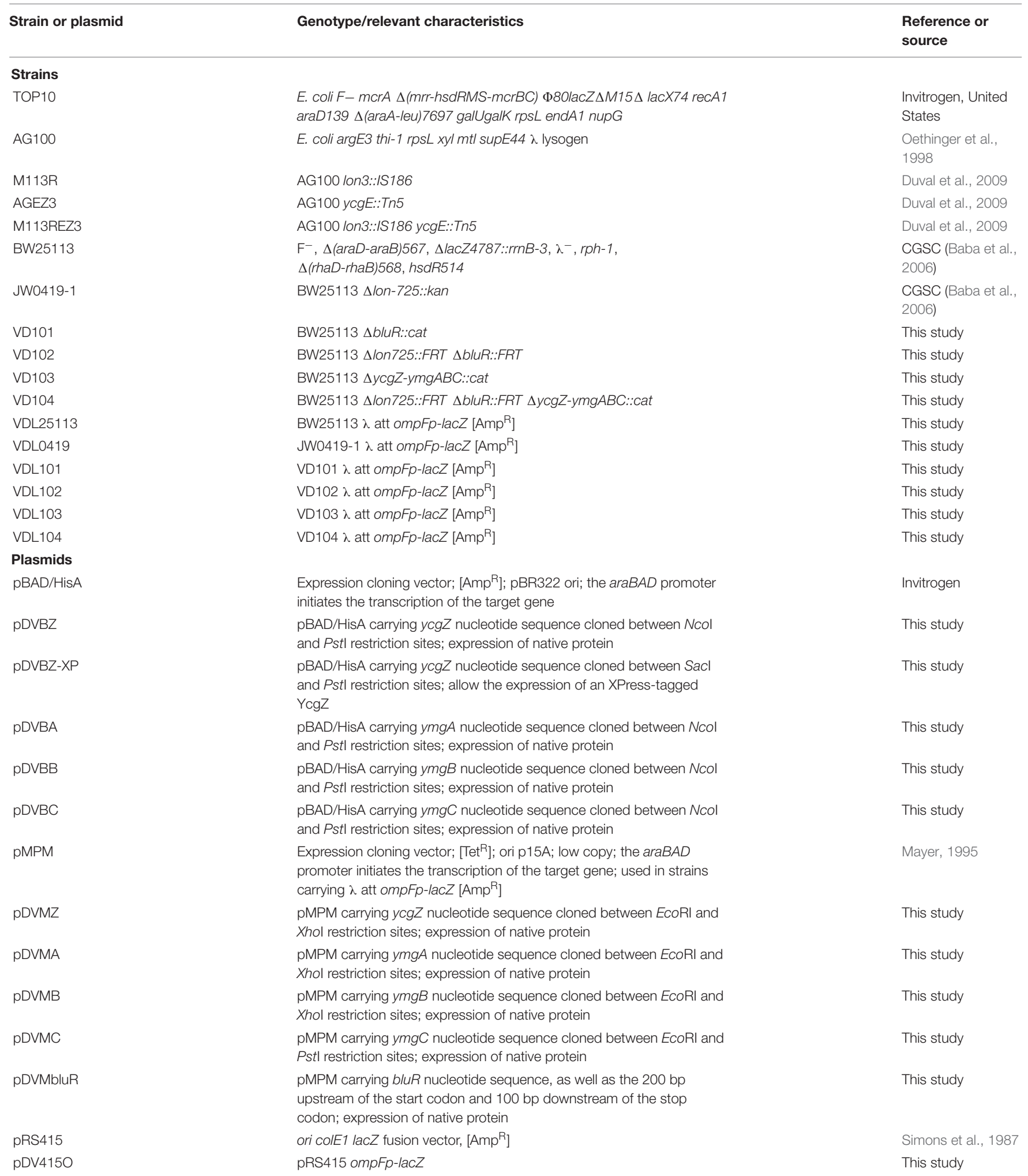




\section{Gene Deletion}

Targeted deletion of bluR and $y c g Z-y m g A B C$, and subsequent marker removal were made using the $\lambda$ Red recombinase method previously described (Datsenko and Wanner, 2000). The Flp recombination target (FRT)-flanked chloramphenicol resistance gene (cat) has been amplified by PCR from plasmid pKD3 using primers listed in Supplementary Table S1. bluR-PA/bluR-PB and $y c g Z-P A / y m g C-P B$ primers contain sequences upstream and downstream of bluR and of $y c g Z-y m g A B C$ operon, respectively. The PCR product was gel-purified and concentrated by ethanol precipitation. Transformants carrying the Red helper plasmid pKD46 were then grown in LB medium with $100 \mu \mathrm{g} \mathrm{ml}{ }^{-1}$ ampicillin and $10 \mathrm{mM} \mathrm{L}$-arabinose at $30^{\circ} \mathrm{C}$ to an optical density at $600 \mathrm{~nm}\left(\mathrm{OD}_{600}\right)$ of 0.6 and then made electrocompetent. Electroporation was done using $200 \mathrm{ng}$ of PCR product. Chloramphenicol resistant clones were selected on LB agar plates containing chloramphenicol $12 \mu \mathrm{g} \mathrm{ml}^{-1}$. Correct integration of the cat gene in the targeted genes was verified by PCR using the primers listed in Supplementary Table S1. Appropriate chloramphenicol resistant clones were subsequently transformed with the pCP20 plasmid and ampicillin resistant clones were selected at $30^{\circ} \mathrm{C}$ on $\mathrm{LB}$ agar plates containing ampicillin $100 \mu \mathrm{g} \mathrm{ml}^{-1}$. The transformants were then colonypurified non-selectively at $42^{\circ} \mathrm{C}$ on LB agar and then tested for loss of ampicillin and chloramphenicol resistance. Deletions were further verified by PCR using the primers listed in Supplementary Table S1.

\section{LacZ Transcriptional Fusion and $\beta$-Galactosidase Assays}

To construct the plasmid pDV415O, amplification of $o m p F$ promoter (PompF) was carried out by PCR using chromosomal DNA from strain E. coli AG100 as template and the primers $o m p F 1$ and ompF2 listed in Supplementary Table S1. The PompF fragment was $273 \mathrm{bp}$ long (from -273 to +1 relative to the transcription start) and was cloned into the pGEM-T Easy vector (Promega) following the manufacturer instruction. The resulting plasmid was digested with $E c o$ RI and $B a m H I$ and the fragment corresponding to PompF was ligated to the similarly cut vector pRS415 yielding the plasmids pDV415O. The sequence of the PompF-lacZ fusion in pDV415O was then verified at the Tufts University Core Facility. Insertion of PompF-lacZ into E. coli chromosome was realized as followed. Recombination between the pDV415O and $\lambda$ RZ5 (Silhavy et al., 1984; Simons et al., 1987) resulted in a lysate bearing $\lambda$ RZ5 (PompF-lacZ). This was used to infect strains BW25113, a $\lambda$ - and lac- strain of E. coli. $A m p^{R}$ Lac+ lysogens were selected and purified on LB agar containing ampicillin $20 \mu \mathrm{g} \mathrm{ml}^{-1}$ and X-Gal (5-bromo-4-chloro3 -indolyl- $\beta \mathrm{D}$-galactopyranoside) $40 \mu \mathrm{g} \mathrm{ml}^{-1}$. Lysates from these lysogens were then used to infect at low multiplicity of infection $(\mathrm{MOI}=0.005)$ strain BW25113 and derivative mutants. $A m p^{\mathrm{R}}$ Lac+ lysogens were again isolated and the resulting strains were confirmed by PCR, as previously described (Powell et al., 1994), to have a single copy of the transcriptional fusion located in the $\lambda$ att site on the chromosome. To assess the $\beta$-galactosidase (LacZ) activity, overnight cultures of fresh colonies of E. coli carrying a chromosomal $\lambda$ PompF-lacZ fusion were grown in LB medium containing ampicillin $20 \mu \mathrm{g} \mathrm{ml}^{-1}$ and were subsequently diluted to an $\mathrm{OD}_{600}$ of 0.05 in identical medium for growth with no antibiotic added. When the $\mathrm{OD}_{600}$ reached $0.6, \beta$-galactosidase (LacZ) activity was assayed by first rendered the cells permeable with $0.005 \%$ sodium dodecyl sulfate and $0.05 \%$ chloroform. LacZ activity was expressed in Miller units as previously described (Miller, 1972). All assays were carried out at least in three independent experiments.

\section{RNA Isolation}

Fresh colonies of $E$. coli strains were grown overnight (14-16 h) in $3 \mathrm{ml}$ of LB medium. The cultures were then diluted to an $\mathrm{OD}_{600}$ of 0.05 in $3 \mathrm{ml}$ of identical fresh medium and cells were grown until an $\mathrm{OD}_{600}$ of $\sim 0.6$. The total RNAs were isolated from $0.5 \mathrm{ml}$ of culture using the Trizol Reagent (Thermo Fisher Scientific) following the manufacturer protocol. Directly after the preparation of the RNAs, the integrity of the RNAs was evaluated on a bleach gel stained with ethidium bromide (Aranda et al., 2012). The RNAs amount was quantified by absorbance at $260 \mathrm{~nm}$ (A260) and purity was evaluated by a A260/A280 ratio > 1.9 and a A260/A230 ratio > 1.7 using a Nanodrop ND1000 spectrophotometer (Thermo Fisher Scientific). RNAs were stored for no more than 3 days at $-80^{\circ} \mathrm{C}$ before DNase treatment and cDNA synthesis (see Reverse Transcription and Quantitative PCR Analysis).

\section{Reverse Transcription and Quantitative PCR Analysis}

Two micrograms of purified RNAs were treated using the Turbo $^{\mathrm{TM}}$ DNase (Thermo Fisher Scientific) following the manufacturer instructions. A total of $500 \mathrm{ng}$ of RNAs was then used to synthesize cDNA by reverse transcription using the Quantitect Reverse Transcription kit (Qiagen) and following the manufacturer instructions. To control for chromosomal DNA contamination, the reverse transcription step was also performed with reaction mixtures containing no reverse transcriptase and was used as a negative control in subsequent quantitative PCR (qPCR) reactions. Primers used for the $\mathrm{qPCR}$ were designed using the online PrimerQuest tool from Integrated DNA Technologies and are listed in Supplementary Table S1. Amplification efficiency and specificity for each set of primers are reported in Supplementary Figure S1. All qPCR reactions were performed using a Roche LightCycler 480 instrument II. The following experimental run protocol was used: UDP activation $\left(50^{\circ} \mathrm{C}\right.$ for $\left.2 \mathrm{~min}\right)$, denaturation $\left(95^{\circ} \mathrm{C}\right.$ for $\left.2 \mathrm{~min}\right)$, quantification program repeated 40 times (denaturation at $95^{\circ} \mathrm{C}$ for $5 \mathrm{~s}$, anneal/extend $60^{\circ} \mathrm{C}$ for $30 \mathrm{~s}$ with a single fluorescence measurement), melting curve program $\left(60-95^{\circ} \mathrm{C}\right.$ with a heating rate of $0.15^{\circ} \mathrm{C} \mathrm{s}^{-1}$ and a continuous fluorescence measurement). Reactions were carried out in $20 \mu \mathrm{l}$ with $2 \mu \mathrm{l}$ of diluted cDNA, $0.4 \mu \mathrm{l}$ of $10 \mu \mathrm{M}$ forward primer $(0.2 \mu \mathrm{M}$ final concentration), $0.4 \mu \mathrm{l}$ of $10 \mu \mathrm{M}$ reverse primer $(0.2 \mu \mathrm{M}$ final concentration), $7.2 \mu \mathrm{l} \mathrm{H}_{2} \mathrm{O}$ and $10 \mu \mathrm{l}$ of the Power Up SYBR Green Master Mix (Applied Biosystems by Life Technologies). After the reverse transcription step, the cDNA samples were diluted fivefold and 


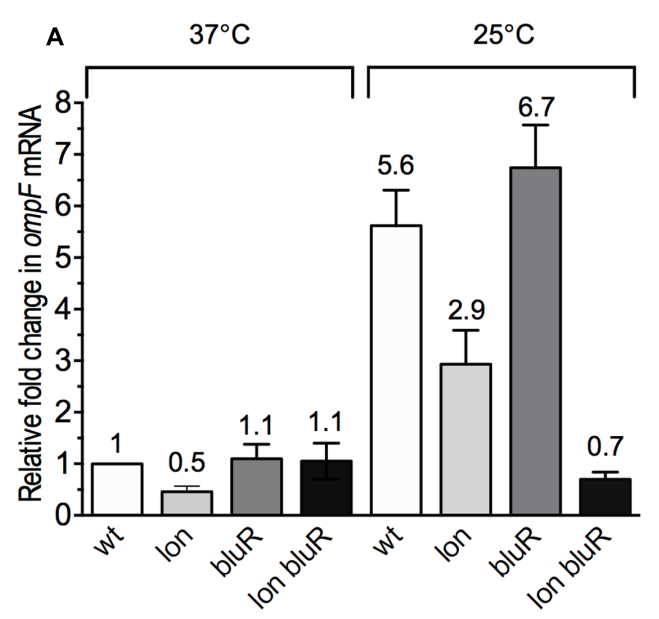

B

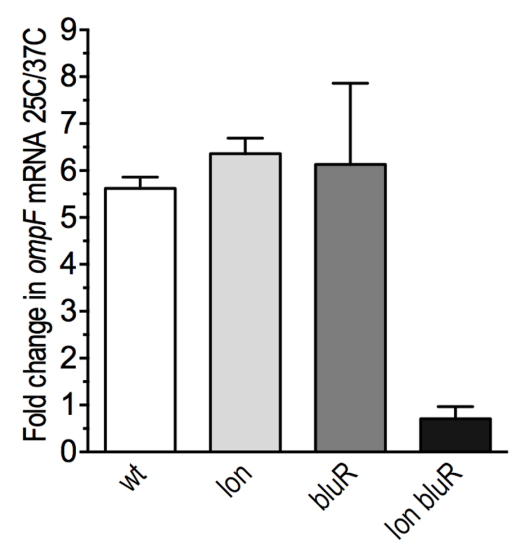

FIGURE 2 | Effect of lon and bluR mutations on ompF mRNA levels in E. coli grown at 25 and $37^{\circ} \mathrm{C}$. The cells were grown to exponential phase (optical density at $600 \mathrm{~nm} \sim 0.6$ ) in LB medium. Total RNAs were prepared and used to measure the OmpF mRNA levels by RT-qPCR. (A) Fold change in OmpF mRNA levels relative to the wild type strain AG100 grown at $37^{\circ} \mathrm{C}$. (B) Fold change in OmpF mRNA levels for all strains grown at 25 versus $37^{\circ} \mathrm{C}$. The numbers represent the means and standard deviations of expression levels from three independent experiments performed in duplicate. AG100, wt; M113R, Ion; AGEZ3, bluR; M113REZ3, Ion bluR. See Supplementary Tables S2, S3 for details.

used as templates for qPCR amplification of $g a p A, o m p F$, and $y c g Z$. A mix with no cDNA was also prepared (non-template control, NTC) and was run in parallel. NTC wells did either gave a $\mathrm{C}_{\mathrm{T}}>35$ or no $\mathrm{C}_{\mathrm{T}}$ at all. We quantified the relative expression of $o m p F$ and $y c g Z$ transcripts to the reference gene gapA. Using the Pfaffl method (Pfaffl, 2001), we determined the ratio $\mathrm{R}$ of a transcript expressed in a sample versus that expressed in the wild type strain grown at $37^{\circ} \mathrm{C}$ (see $\mathrm{C}_{\mathrm{T}}$ and calculations in Supplementary Tables S2-S7). gapA encodes the glyceraldehydes 3-phosphate deshydrogenase-A.

\section{Statistical Analysis}

We report the average (mean) and the standard deviation (SD) from at least three experimental values. In Figures $\mathbf{2 B}$ and $\mathbf{4 B}$, we report the ratio $\mathrm{R} 3( \pm \mathrm{SD} 3)$ of two numbers $\mathrm{R} 1 \pm \mathrm{SD} 1$ and $\mathrm{R} 2 \pm \mathrm{SD} 2$, with $\mathrm{R} 3=\frac{R 2}{R 1}$ and $\frac{S D 3}{R 3}=\sqrt{\left(\frac{S D 1}{R 1}\right)^{2}+\left(\frac{S D 2}{R 2}\right)^{2}}$. The statistical significance of differences between two averages was determined by a Student's $t$-test (two independent samples, with two-tailed distribution) using GraphPad Prism software. ${ }^{1}$

\section{Steady-State Levels of Protein and Stability Assays}

Overnight culture of E. coli wild type (BW25113) and lon (JW0419-1) strains carrying plasmids $\mathrm{pBAD} / \mathrm{His}$ A and derivative pDVBZ, pDVBZ-XP, pDVBA, pDVBB, and $\mathrm{pDVBC}$ were grown in $\mathrm{LB}$ medium in the presence of $100 \mu \mathrm{g} \mathrm{ml} \mathrm{m}^{-1}$ ampicillin. Fresh identical medium supplemented with L-arabinose was then inoculated to an optical density measured at $600 \mathrm{~nm}$ of 0.05 and cells were grown at 37 or $25^{\circ} \mathrm{C}$ to $\mathrm{OD}_{600}$ of 1 . Whole cell extracts were prepared for analysis of the steady-state levels of protein. To assess the intracellular stability of YcgZ, $150 \mu \mathrm{g} \mathrm{ml}^{-1}$

${ }^{1}$ https://www.graphpad.com/scientific-software/prism/ chloramphenicol was added to stop the proteins synthesis and the cultures were kept at the indicated temperatures. Samples to be used for preparing whole cell extracts were removed at indicated times (0-60 min). Cell extracts were prepared as follows: $1 \mathrm{ml}$ of culture was centrifuged and the cells pellet suspended in $200 \mu \mathrm{l}$ of lysis buffer per $\mathrm{OD}_{600}$ of 1 [Tris- $\mathrm{HCl} 10 \mathrm{mM}$ pH 8.0, EDTA $0.5 \mathrm{mM}, \mathrm{CaCl}_{2} 10 \mathrm{mM}$, and 1 unit $\mathrm{ml}^{-1}$ of DNase (Promega)]. Cells were sonicated on ice two times 20 pulses using a Branson Sonifier 250 and the following parameters: output control $=1$ and a duty cycle $=50 \%$. Protein concentration was determined using the Pierce $660 \mathrm{~nm}$ Protein Assay Reagent and bovine serum albumin as a standard (Thermo Fisher Scientific). Eight micrograms of proteins were separated on a $16 \%$ acrylamide gel in denaturing condition (100 mM Tris, $100 \mathrm{mM}$ Tricine, and $0.1 \%$ SDS). The gels were stained with Coomassie Brilliant Blue R-250 (Sigma-Aldrich) or used for western blot analysis.

\section{Detection of XPress-Tagged YcgZ by Western Blot}

After separation on a $16 \%$ acrylamide gel, the proteins were electro-transferred to a nitrocellulose membrane (Millipore, Billerica, MA, United States). The membrane was incubated overnight at $4^{\circ} \mathrm{C}$ in Tris-borate-saline (TBS) buffer supplemented with $3 \%$ milk powder. The membrane was then incubated for $2 \mathrm{~h}$ at room temperature with monoclonal anti-XPress antibodies (Thermo Fisher Scientific) diluted in TBS $(1 / 6,000)$. After three 15 min washes with TTBS (TBS supplemented with $0.05 \%$ Tween 20), the membrane was incubated for $2 \mathrm{~h}$ with alkaline phosphatase-coupled anti-mouse IgG antibodies (Promega) diluted $1 / 10,000$ in TBS followed by three $15 \mathrm{~min}$ washes with TTBS and two $5 \mathrm{~min}$ washes with TBS. XPress-YcgZ was visualized by adding 5-bromo-4-chloro-3-indolyl phosphate and nitroblue tetrazolium following the manufacturer's instructions (Promega). 


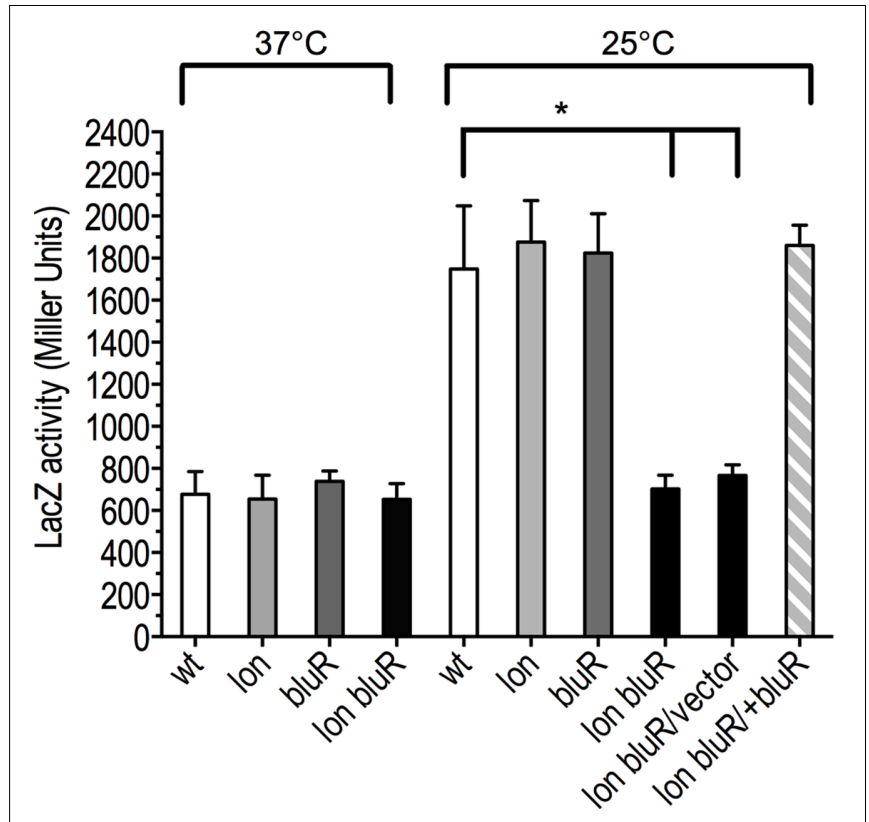

FIGURE 3 | Ion and bluR mutations lead to decreased ompF transcription at $25^{\circ} \mathrm{C}$. The $\beta$-galactosidase activity (Miller units) of a single chromosomal copy of PompF-lacZ was measured for cells grown to exponential phase (optical density at $600 \mathrm{~nm} \sim 0.6$ ) in LB medium at 25 and $37^{\circ} \mathrm{C}$. Wild type, VDL25113; Ion, VDL0419; bluR, VDL101; Ion bluR, VDL102; vector, pMPM; +bluR, pDVMbluR. Numbers represent the means and standard deviations from at least three independent experiments. Statistically significant differences for a mutant compared to wild type are shown as asterisk $\left({ }^{*} P<0.05\right)$.

\section{RESULTS}

\section{Escherichia coli Carrying Mutations in both Ion and bluR Failed to Increased OmpF Expression at $25^{\circ} \mathrm{C}$}

When grown at $37^{\circ} \mathrm{C}$, E. coli expresses low amount of $\mathrm{OmpF}$ in the outer membrane, while decreased temperatures lead to increased levels of the porin (Pratt et al., 1996; Nikaido, 2003). A previous study performed in our laboratory demonstrated that E. coli carrying mutations in both lon and bluR loci resulted in significantly lower amounts of the porin when the cells were grown under low temperature conditions (see protein level of OmpF in Duval et al., 2009). To better characterize the effect of lon and bluR on ompF expression, we performed reverse transcription and qPCR (RT-qPCR) and compared the level of OmpF messenger in wild type E. coli AG100 and derivative strains carrying mutations in lon, bluR, and lon bluR. All strains were grown at 37 and $25^{\circ} \mathrm{C}$. Our data show that wild type E. coli grown at $25^{\circ} \mathrm{C}$ induces $\mathrm{OmpF}$ expression by approximately sixfold when compared to that of wild type E. coli grown at $37^{\circ} \mathrm{C}$ (Figures 2A,B). Our data also indicate that a single mutation in bluR has no significant effect on OmpF mRNA level, while a lon mutation slightly decreases the expression of OmpF at both temperatures (Figure 2A). Nevertheless the fold change in $\mathrm{OmpF}$ mRNA for both lon and bluR mutants grown at 25 versus $37^{\circ} \mathrm{C}$ is similar to that of wild type AG100 (Figure 2B). However, a lon bluR mutant carrying both mutations fails to increase ompF expression when grown at $25^{\circ} \mathrm{C}$.

To further characterize the role of Lon and BluR in regulating OmpF expression, we constructed a transcriptional reporter fusion of ompF promoter with lacZ (PompF-lacZ). The resulting fusion did not carry ompF $5^{\prime}$-UTR affected by MicF (Andersen and Delihas, 1990), but instead carried lacZ $5^{\prime}$-UTR. In this case, we prevented post-transcriptional effects on ompF $5^{\prime}$ UTR. A single copy of the reporter fusion was then integrated at the $\operatorname{att}(\lambda)$ site of wild type E. coli BW25113, a lac- $\lambda-$ strain, and of derivative mutants lon, bluR, and lon bluR. LacZ activity was then assayed in cells grown at 37 and $25^{\circ} \mathrm{C}$. Our results from the $\beta$-galactosidose assays show that transcription of PompF-lacZ increases by approximately threefold in the wild type strain grown under low temperature conditions (Figure 3). In contrast, the lon bluR double mutant fails to increase PompF-lacZ expression at $25^{\circ} \mathrm{C}$ and displays similar PompF-lacZ activities at 25 and $37^{\circ} \mathrm{C}$ (Figure 3). Plasmid mediated expression of bluR in the lon bluR mutant restores PompF-lacZ levels similar to that of wild type (Figure 3). Our data also show that a single mutation in either lon or bluR has no effect on PompF-lacZ transcription (Figure 3). We suspect that the decreased OmpF mRNA level observed for the lon mutant (see above) is likely due to a lower stability of the messenger in the absence of the Lon protease since no difference is detected at the transcriptional level.

The simplest model illustrating the effect of both lon and bluR mutations on ompF transcription under the growth conditions used in our experiments implies that BluR represses a locus coding for an intermediate protein that is a substrate of the Lon protease. This intermediate protein would act as a repressor of the $o m p F$ promoter. In this model, the inactivation of bluR leads to an increased transcription of the intermediate locus, and only in the absence or with a reduced activity of Lon, can the intermediate protein accumulate and considerably repress $o m p F$ at $25^{\circ} \mathrm{C}$, a condition that normally permits increased expression of the porin in wild type E. coli. In an otherwise direct activation of ompF promoter by BluR, deletion of $b l u R$ alone would lead to decreased ompF transcription.

\section{BluR Controls the Temperature-Dependent Expression of the $y c g Z-y m g A B C$ Operon}

We subsequently aimed to identify the intermediate locus controlled by BluR and involved in the regulation of ompF expression. BluR has been previously described to directly repress the transcription of the $y c g Z-y m g A B C$ operon $(Z A B C$; Tschowri et al., 2012). This operon encodes small proteins of 78-90 amino acid residues involved in biofilm formation through a mechanism that is yet to be determined (Tschowri et al., 2009). Using RT-qPCR, we measured the expression of the $Z A B C$ operon in AG100 (wt), AGEZ3 (bluR), and M113REZ3 (lon bluR) derivative strains. When comparing YcgZ mRNA levels at 37 and $25^{\circ} \mathrm{C}$ for the wild type strain, our results shows a $\sim 46-$ fold increased expression of $y c g Z$ when the cells were grown at ambient temperature (Figures $4 \mathbf{A}, \mathbf{B}$ ). Our data also determine that a bluR mutant increases expression of the $Z A B C$ operon by 


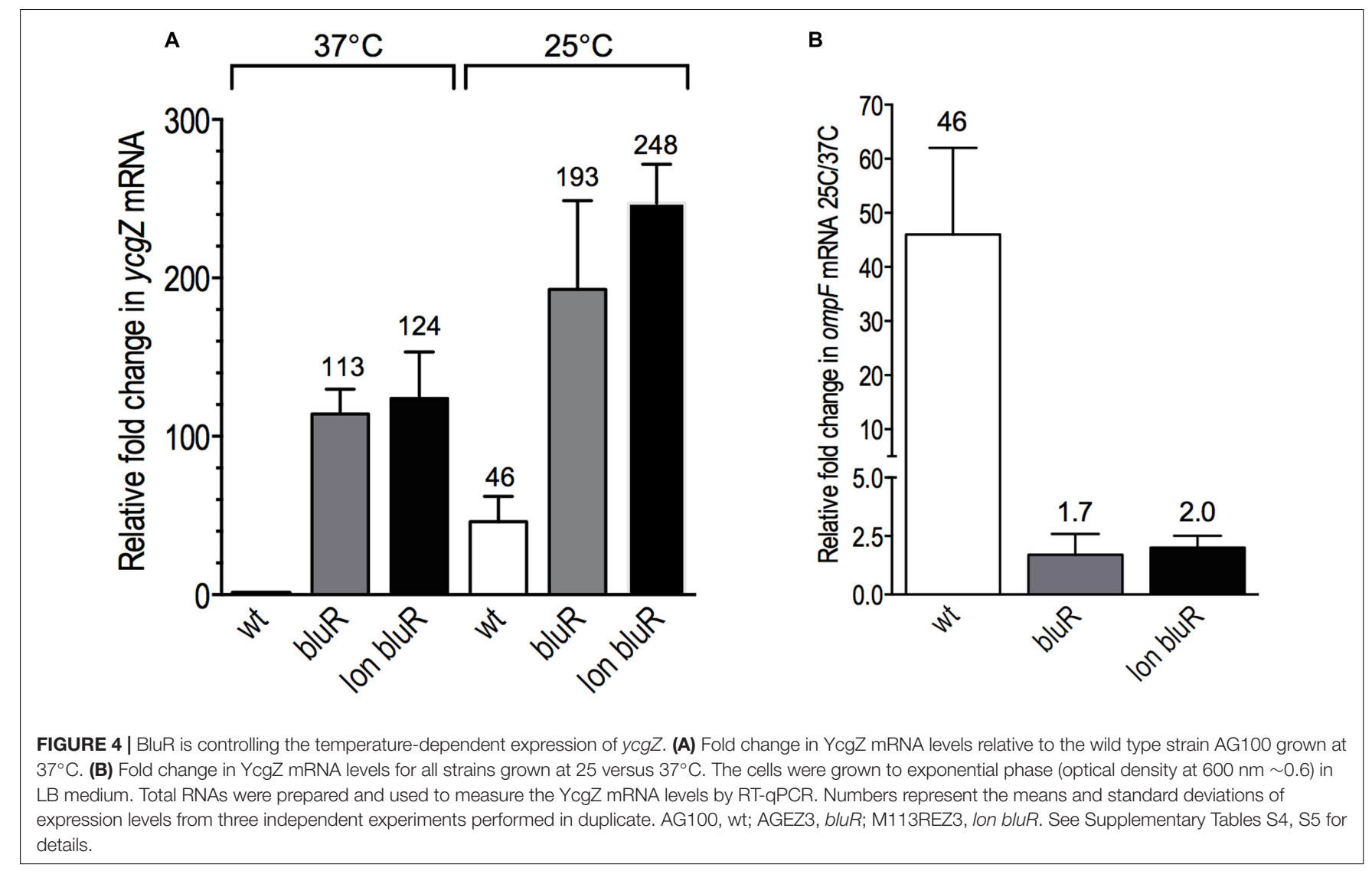

$\sim 100$ - and $\sim 4$-fold in cells grown at 37 and $25^{\circ} \mathrm{C}$, respectively (Figure 4A), indicating a strong repression of the $y c g Z$ promoter by BluR at $37^{\circ} \mathrm{C}$. It was previously shown by Tschowri et al. (2009) that BluR-DNA interaction is released in the presence of BluF, a direct antagonist of BluR whose activity is induced by low temperature. We believe that the weaker repression of the $y c g Z$ promoter observed at $25^{\circ} \mathrm{C}$ likely comes from the BluR inactivation by BluF under these growth conditions. At $37^{\circ} \mathrm{C}$, BluR repressor is fully active and its deletion leads to a large de-repression of the $y c g Z$ promoter. Our results in Figure 4A also show that the addition of a lon mutation to a bluR mutation (lon bluR) leads to a slight increased in $y c g Z$ mRNA levels when compared to that of bluR. For AGEZ3 (bluR) and M113REZ3 (lon bluR), the low temperature mediated induction is only approximately twofold, overall indicating that bluR is mainly responsible for the temperature-dependent expression of $y c g Z$.

\section{YcgZ Represses ompF Transcription}

We then investigated whether the $Z A B C$ operon, which is de-repressed at $25^{\circ} \mathrm{C}$, was involved in the control of ompF expression. In our model, if one of the proteins encoded by the $Z A B C$ operon accumulates in a lon bluR strain and represses $o m p F$, we expect to see an increased $o m p F$ expression when the $Z A B C$ operon is deleted, i.e., in strain lon bluR ZABC. Using RT-qPCR, we compared OmpF mRNA levels in wild type, lon bluR and lon bluR ZABC strains grown at 37 and $25^{\circ} \mathrm{C}$. When grown at $37^{\circ} \mathrm{C}$, the three strains show similar OmpF mRNA levels (Figure 5A). Under low temperature growth conditions, the lon bluR ZABC strain expressed OmpF mRNA level similar to that of the wild type strain (Figure 5A). We further confirmed that the $Z A B C$ operon was involved in the control of $o m p F$ transcription using our PompF-lacZ reporter fusion; Figure 5B shows that deletion of the $Z A B C$ operon in a lon bluR background restores LacZ activity similar to that of the wild type. Taken together, our results suggest that the $\mathrm{ZABC}$ operon encodes a protein able to repress $o m p F$ expression. To further identify this repressor, we used a low copy $\mathrm{pBAD}$ vector allowing the expression of a target gene from the L-arabinose-dependent promoter araBAD. We independently expressed $y c g Z$, $y m g A, y m g B$, and $y m g C$ in the lon bluR $Z A B C$ strain and subsequently measured the LacZ activity in the transformants grown at $25^{\circ} \mathrm{C}$ in the presence of L-arabinose. Our results show that the activity of PompF-lacZ decreases in response to increasing amount of YcgZ, while YmgA, YmgB, and YmgC have no significant effect on PompF-lacZ activity (Table 2 and see also Supplementary Figure S2). While our results identifies YcgZ as a repressor of the $o m p F$ promoter and our data show that $y c g Z$ expression is high in a bluR mutant (Figure 4), a bluR mutant does not decrease $o m p F$ transcription (Figures 2, 3). However, a lon bluR strain grown at $25^{\circ} \mathrm{C}$ expresses less ompF transcript than the $b l u R$ mutant. These results strongly suggest that YcgZ is unstable in the presence of Lon under the growth conditions used in our experiments. That a lon bluR strain grown at $37^{\circ} \mathrm{C}$ does not decrease transcription of $o m p F$ is probably due 

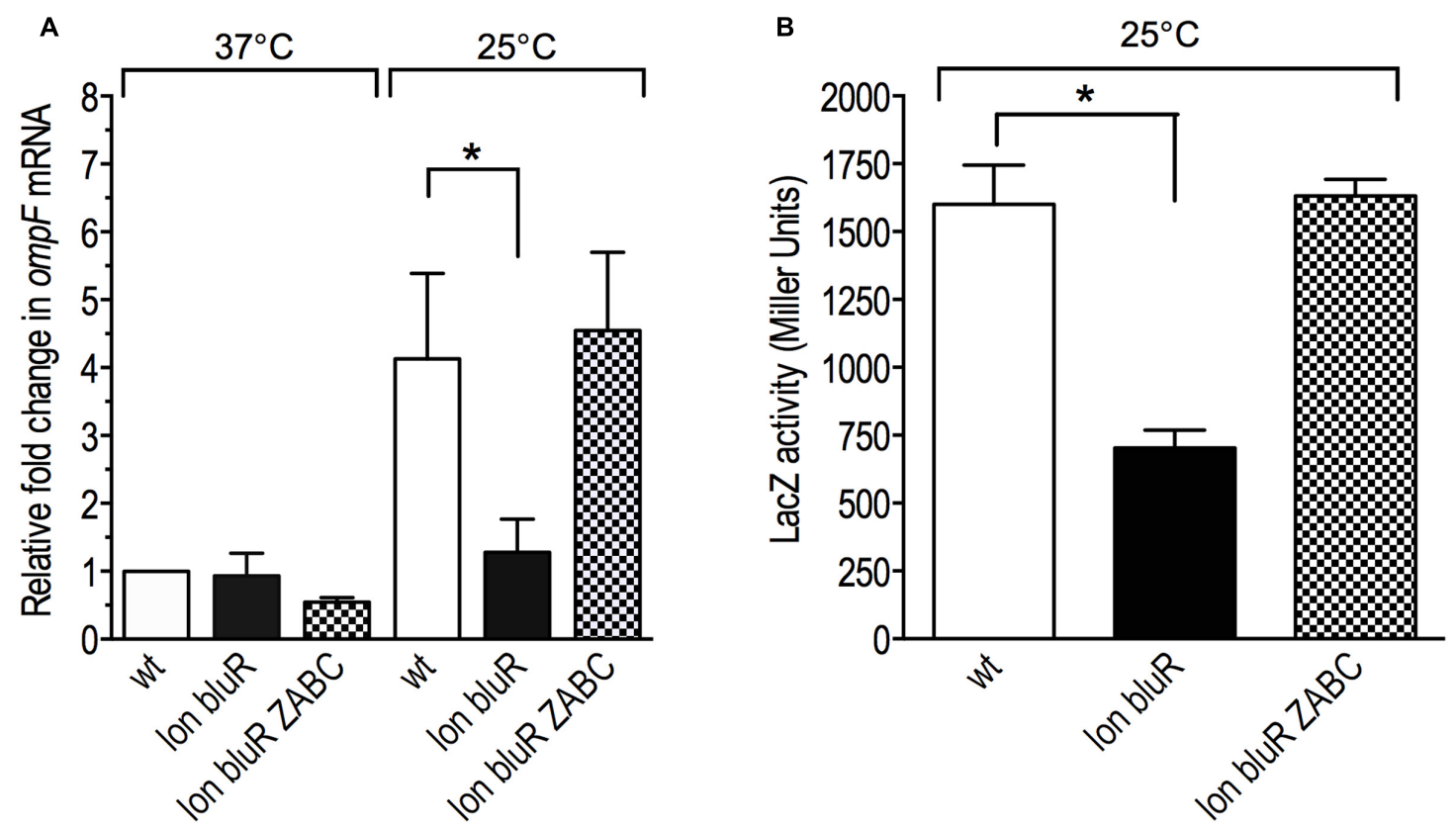

FIGURE 5 I Ion and bluR mutations decrease ompF transcription via the ycgZ-ymgABC operon. The cells were grown to exponential phase (optical density at $600 \mathrm{~nm} \sim 0.6$ ) in LB medium at 25 and $37^{\circ} \mathrm{C}$. Total RNAs were prepared and used to measure the OmpF mRNA levels by RT-qPCR. (A) Fold change in OmpF mRNA levels relative to the wild type strain grown at $37^{\circ} \mathrm{C}$. (B) The $\beta$-galactosidase activity (Miller units) of a single chromosomal copy of PompF-lac $Z$ was measured for cells grown to exponential phase in LB medium at $25^{\circ} \mathrm{C}$. wt, VDL25113; Ion bluR, VDL102; lon bluR ycgZ-ymgABC (VDL104). The means and standard deviations of at least three independent experiments are shown. Statistically significant differences for a mutant compared to wild type are shown as asterisk $\left({ }^{*} P<0.05\right)$. See Supplementary Table S6, S7 for details.

to growth conditions that inherently lead to a high repression of $o m p F$ expression. In this case, YcgZ amount may be too low to further repress the $o m p F$ promoter.

TABLE 2 | Expression of PompF-lacZ in E. coli VDL104 (Jon bluR ycgZ-ymgABC) grown to exponential phase in LB medium at $25^{\circ} \mathrm{C}$.

\begin{tabular}{|c|c|c|c|}
\hline \multirow[t]{2}{*}{ Plasmids } & \multirow[t]{2}{*}{ L-Arabinose \% } & \multicolumn{2}{|c|}{ LacZ activity } \\
\hline & & Miller units & $\%$ Controla $^{a}$ \\
\hline \multirow[t]{4}{*}{ pMPM } & 0 & $1513 \pm 258$ & \\
\hline & 0.005 & $1279 \pm 201$ & \\
\hline & 0.05 & $1066 \pm 152$ & \\
\hline & 0.5 & $1017 \pm 145$ & \\
\hline \multirow[t]{4}{*}{ pDVMZ (+ycgZ) } & 0 & $1195 \pm 190$ & 79 \\
\hline & 0.005 & $851 \pm 135$ & 66 \\
\hline & 0.05 & $385 \pm 49$ & 36 \\
\hline & 0.5 & $225 \pm 16$ & 21 \\
\hline \multirow[t]{2}{*}{ pDVMA (+ymgA) } & 0 & $1221 \pm 273$ & 81 \\
\hline & 0.5 & $921 \pm 57$ & 91 \\
\hline \multirow[t]{2}{*}{ pDVMB $(+y m g B)$} & 0 & $1544 \pm 69$ & 102 \\
\hline & 0.5 & $766 \pm 140$ & 75 \\
\hline \multirow{2}{*}{ pDVMC (+ymgC) } & 0 & $1324 \pm 98$ & 88 \\
\hline & 0.5 & $1068 \pm 67$ & 105 \\
\hline
\end{tabular}

apercentage of LacZ activity compared to the strain carrying the empty vector (pMPM).

\section{YcgZ is a Substrate of the Lon Protease}

To evaluate whether YcgZ was a substrate of the Lon protease, we compared YcgZ protein amount in E. coli wild type and lon mutant. For completion purpose, we also evaluated the stability of YmgA, YmgB, and YmgC. Lacking antibodies that can specifically interact with the proteins, we decided to evaluate the steady-state level of each native protein when overexpressed from an $a r a B A D$ promoter using $\mathrm{pBAD}$ derivative plasmids (see Table 1). Protein expression was compared between BW25113 (wild type) and JW0419-1 (lon) carrying the plasmids and grown in the presence of L-arabinose. Our experiments indicated that the amount of YcgZ was significantly lower when expressed in the wild type strain, while a lon mutant accumulated a large amount of YcgZ (Figure 6A). Of note, we observed this phenomenon when the cells were grown at both 25 and $37^{\circ} \mathrm{C}$. We verified that the lower amount of YcgZ in the wild type was not due to a lesser expression of $y c g Z$ by quantifying $y c g Z$ messenger levels. RT-qPCR experiments showed that $y c g Z$ was similarly expressed in both strains (see Supplementary Table S8), suggesting that the higher level of YcgZ protein observed in the lon mutant is likely due to a higher stability of the protein in the absence of Lon. Our data illustrated in Figure 6A also shows similar amounts of YmgA and YmgC proteins when overexpressed in the wild type and in the lon strains. We could not detect significant amount of YmgB in any of the strains tested even though high level of $y m g B$ messenger was measured by RT-qPCR in both strains (data not shown). Using an XPress-tagged YcgZ (XPYcgZ), we 


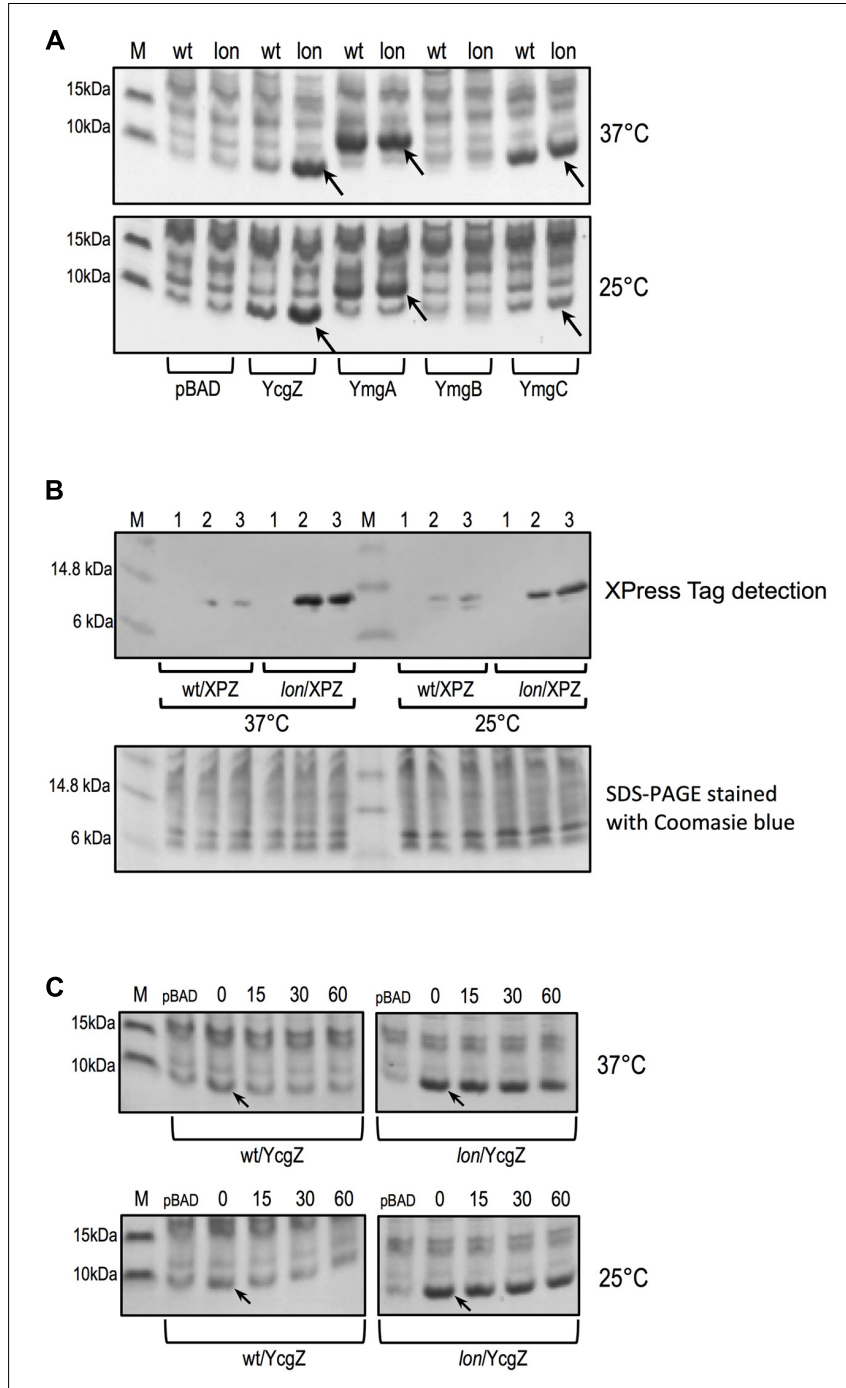

FIGURE 6 | Protein levels of YcgZ, YmgA, YmgB, and YmgC in E. coli wild type (BW25113) and lon mutant (JW0419-1). (A) Steady-state level of native YcgZ, YmgA, YmgB, and YmgC expressed with plasmids pBAD (empty plasmid), pDVBZ (YcgZ), pDVBA (YmgA), pDVBB (YmgB), and pDVBC (YmgC), respectively and $0.05 \%$ of L-arabinose. (B) Steady-state level of XPress-tagged YcgZ expressed with pDVBZ-XP plasmid and detected by immunoblotting. 1, no L-arabinose; 2, 0.005\% L-arabinose; 3, 0.05\% L-arabinose. (C) Stability of native YcgZ expressed with plasmid pDVBZ. The numbers indicate the time in minutes after addition of $150 \mathrm{\mu g} \mathrm{ml}^{-1}$ chloramphenicol. For all experiments, the target gene was expressed from an araBAD promoter using pBAD derivative plasmids. The strains carrying plasmids were grown to an optical density of 1 in the presence of $L$-arabinose at 37 and $25^{\circ} \mathrm{C}$, respectively. Whole cell extracts were then prepared and analyzed by SDS-PAGE and the gels were stained using Coomassie (A,C) The arrow indicates the band corresponding to the expressed protein. Each lane contains $8 \mu \mathrm{g}$ of proteins. M, Benchmark Protein Ladder.

confirmed an L-arabinose-dependent accumulation of YcgZ in the lon strains, while the protein was barely detectable in the wild type (Figure 6B). Additionally, we examined the stability of native YcgZ in the wild type and lon strains after stopping the protein synthesis with chloramphenicol and determining the amount of YcgZ in multiple samples taken over a certain period

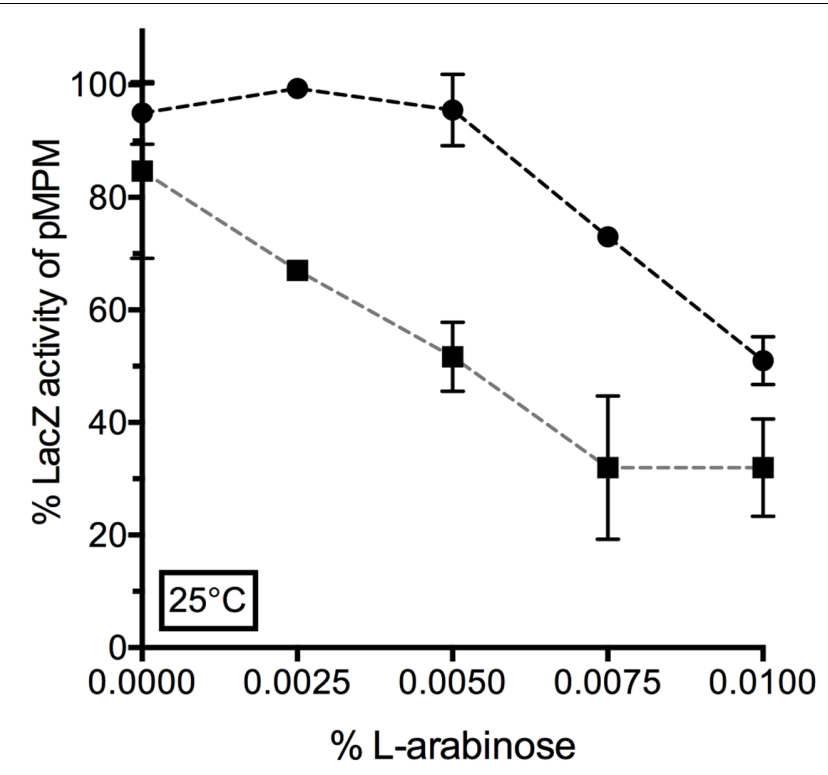

FIGURE 7 | Lon-dependent repression of PompF-lacZ by YcgZ. YcgZ was expressed using the pDVMZ vector in VDL103 (ycgZ-ymgABC $\bullet$ ) and VDL104 (Ion bluR ycgZ-ymgABC $\mathbf{0}$ ) strains. Cells were grown at $25^{\circ} \mathrm{C}$ in LB medium supplemented with increasing concentration of L-arabinose. LacZ activity was measured when the culture reached exponential phase (optical density at $600 \mathrm{~nm} \sim 0.6$ ) and is expressed as a percentage of the LacZ activity measured for the strain carrying the empty pMPM plasmid. The values represent the mean and the standard deviations of a least three independent experiments.

of time (Figure 6C). We observed a decline in YcgZ quantity in the wild type strain, while a high amount of the protein was maintained over time in the lon mutant, demonstrating a significant stability of YcgZ in the absence of Lon.

We further aimed to confirm the lon-dependent repression of $o m p F$ promoter by YcgZ. YcgZ was expressed in the ZABC and lon bluR ZABC mutant strains, both carrying a chromosomal PompF-lacZ fusion and providing both lon+/lon- backgrounds. In the absence of lon, expression of YcgZ significantly decreased LacZ activity with addition of $0.0025 \%$ of L-arabinose (Figure 7). In a lon+ background, similar repression of $o m p F$ promoter was reached by increasing the L-arabinose concentration by at least threefold $(0.0075 \%)$. Ultimately, when a higher concentration of L-arabinose was used ( $>0.01 \%)$, both strains expressed a similar level of LacZ indicating that under those conditions, an abundant level of YcgZ is sufficient to repress $\operatorname{cmp} F$ promoter even in the presence of the Lon protease (Figure 7). Of note, the level of $y c g Z$ transcript measured when $y c g Z$ is expressed from its own promoter is much lower than that expressed from the araBAD promoter with concentration of $\mathrm{L}$-arabinose above 0.01\% (compared Supplementary Tables S4, S5 with Table S8).

\section{DISCUSSION}

OmpF regulation in response to variable growth conditions provides a great example of bacterial adaptive response to the 


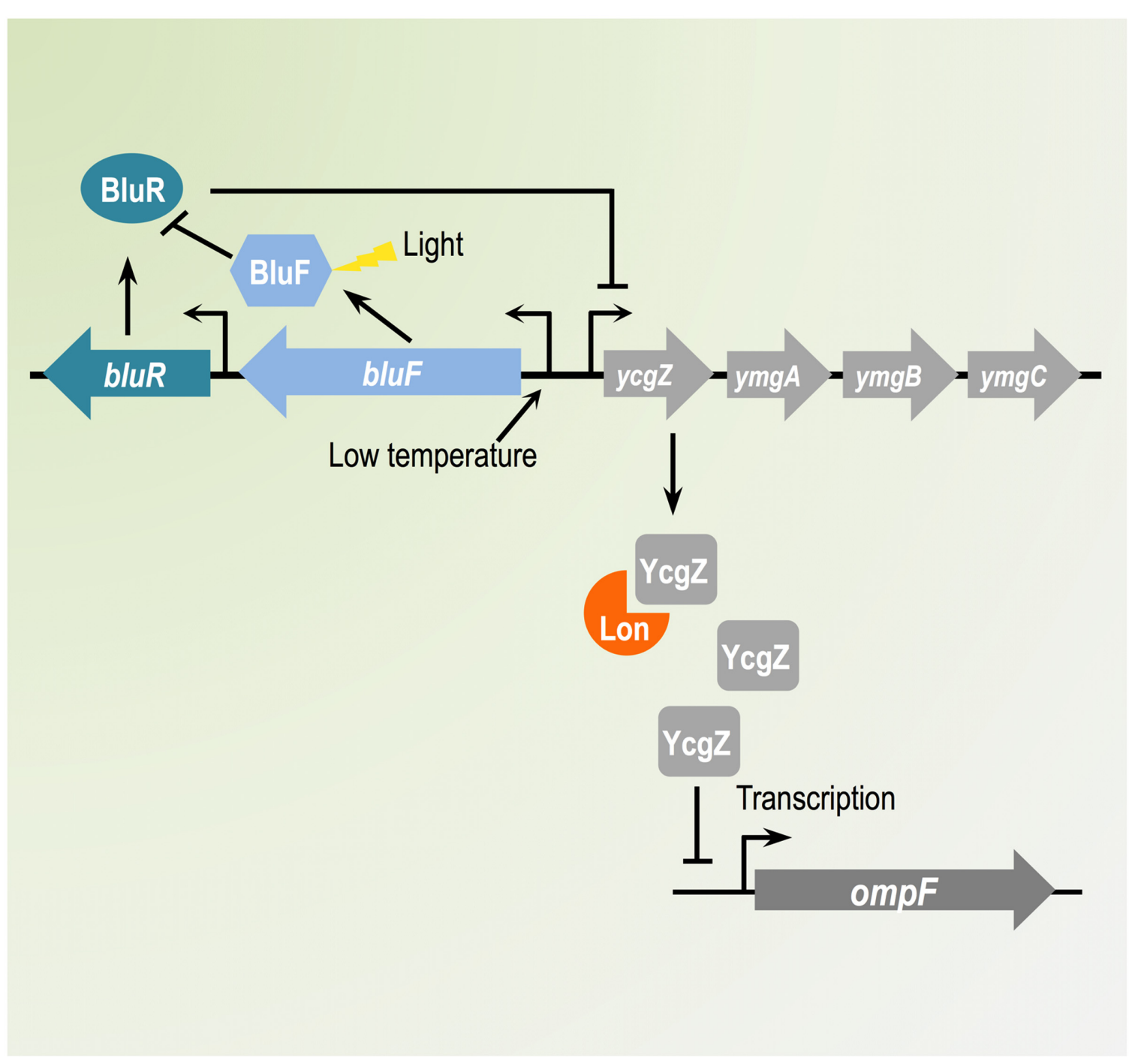

FIGURE 8 | Schematic representation of the regulatory cascade employed by BluR and Lon to control OmpF expression. In Escherichia coli, OmpF expression responds to environmental changes via complex regulatory networks. Our report described a novel pathway controlling OmpF synthesis at low temperature. The ycgZ-ymgABC operon, which transcription is controlled by the BluR-BluF system, encodes YcgZ, a protein highly unstable in the presence of the Lon protease. Increased amount of $\mathrm{YcgZ}$ leads to reduced transcription of ompF, consequently decreasing the amount of OmpF porin.

environment. In this work, we characterize a lon bluR mutant of $E$. coli and we show that transcription of $o m p F$ is impaired when the cells are grown at $25^{\circ} \mathrm{C}$. Our data reveal that both bluR and lon bluR strains expressed high levels of $y c g Z$ transcript, confirming a transcriptional repression by BluR on the $y c g Z$ promoter. We find that the repression of the $y c g Z$ promoter by BluR is strong when the cells are grown at $37^{\circ} \mathrm{C}$, while growth at $25^{\circ} \mathrm{C}$ led to a weaker repression. We also show a high induction of $y c g Z$ expression at $25^{\circ} \mathrm{C}$, which is essentially mediated by bluR. It was previously established that the BluR-DNA interaction is released in the presence of BluF, a direct antagonist of BluR whose activity is induced by low temperature. Inactivation of BluR by BluF consequently led to transcription of the $y c g Z-y m g A B C$ operon (Tschowri et al., 2009). This effect is further increased upon exposure of BluF to blue-light irradiation in addition to the temperature downshift as blue-light activates BluF through conformational changes (Hasegawa et al., 2006; Nakasone et al., 2010).

While we do not describe the specific mechanism by which YcgZ regulates OmpF expression, our study clearly establishes that expression of YcgZ represses ompF transcription. Moreover, our analyses demonstrate a high instability of YcgZ in wild type E. coli, while the protein substantially accumulates and remains stable in a lon mutant, identifying YcgZ as a substrate of the Lon protease. The high instability of YcgZ in the presence of Lon explains why, even though $y c g Z$ expression is large in a bluR mutant at 25 and $37^{\circ} \mathrm{C}$, ompF transcription is not affected. These growth conditions are detrimental to the stability of YcgZ with the activity of Lon being high enough to keep the concentration of YcgZ below the threshold where it can inhibit the ompF promoter. 
In other words, when expressed from its own promoter and under the growth conditions used in our experiments, YcgZ will likely have an effect on the $o m p F$ promoter only if its stability is increased. Growth at temperatures below $25^{\circ} \mathrm{C}$ could reduce the proteolytic activity of Lon, leading to a higher level of YcgZ in the cell. For instance, Yersinia pestis YmoA is a substrate of the Lon protease. Jackson et al. (2004) found that YmoA stability increases as the growth temperature decreases to become stable at $17^{\circ} \mathrm{C}$ (half-life $>3 \mathrm{~h}$ ). Alternatively, the interaction of YcgZ with another yet to be discovered protein could protect YcgZ from degradation by Lon. An example of such phenomenon in E. coli is illustrated with HU- $\alpha$ and HU- $\beta$ proteins, two homologous proteins encoded by hupA and $h u p B$, respectively and which form heterodimers. In the presence of HU- $\alpha, \mathrm{HU}-\beta$ is fairly stable, while in a hupA mutant HU- $\beta$ is degraded by Lon (Bonnefoy et al., 1989); HU- $\alpha$ seems to protect HU- $\beta$ from degradation by Lon.

How YcgZ, a protein of 78 amino acid residues, acts on $o m p F$ promoter is still under investigation. $\mathrm{YmgB}$, a small three-helix protein of 88 amino acids encoded by the $Z A B C$ operon, was shown to display similarity to protein Hha (Lee et al., 2007) and to downregulate curli expression in an RcsB-dependent pathway (Tschowri et al., 2009). It was then proposed that YmgB acts as "connector" of the Rcs phosphorelay. YcgZ could likely work as a small protein connector as well. Interestingly, YmgA and YmgB proteins have been shown to activate colanic acid expression under ambient temperature conditions $\left(16-28^{\circ} \mathrm{C}\right)$, while decreasing curli synthesis (Tschowri et al., 2009). The only known role of YcgZ was to somehow alleviate the activity of both YmgA and YmgB.

\section{CONCLUSION}

Our study identifies $\mathrm{OmpF}$ promoter as a new target regulated by YcgZ, a small pleiotropic regulator, which expression is induced by low temperatures via BluR and is destabilized by the Lon

\section{REFERENCES}

Achouak, W., Heulin, T., and Pagès, J. M. (2001). Multiple facets of bacterial porins. FEMS Microbiol. Lett. 199, 1-7. doi: 10.1111/j.1574-6968.2001.tb10642.x

Andersen, J., and Delihas, N. (1990). micF RNA binds to the 5' end of ompF mRNA and to a protein from Escherichia coli. Biochemistry 29, 9249-9256. doi: 10.1021/bi00491a020

Aranda, P. S., LaJoie, D. M., and Jorcyk, C. L. (2012). Bleach gel: a simple agarose gel for analyzing RNA quality. Electrophoresis 33, 366-369. doi: 10.1002/elps. 201100335

Baba, T., Ara, T., Hasegawa, M., Takai, Y., Okumura, Y., Baba, M., et al. (2006). Construction of Escherichia coli K-12 in-frame, single-gene knockout mutants: the Keio collection. Mol. Syst. Biol. 2, 2006.0008. doi: 10.1038/msb41 00050

Basle, A. M., Qutub, R., Mehrazin, M., Wibbenmeyer, J. A., and Delcour, A. H. (2003). Functional studies on loop deletion mutants of E. coli OmpF porin. Biophys. J. 84, 533A-533A.

Bonnefoy, E., Almeida, A., and Rouvière-Yaniv, J. (1989). Lon-dependent regulation of the DNA binding protein HU in Escherichia coli. Proc. Natl. Acad. Sci. U.S.A. 86, 7691-7695. protease. We believe our results shed a new light on novel signals able to regulate $\mathrm{OmpF}$ porin expression through complex regulatory pathways (see proposed model in Figure 8). The possibility of a more complex regulatory architecture involving other factors not considered in this study is under investigation.

\section{AUTHOR CONTRIBUTIONS}

VD and SL conceived the study. VD, KF, and JB performed the experiments. VD analyzed data. VD and SL prepared the manuscript and all the authors contributed to preparing the final version of the manuscript. All authors read and approved the final version of the manuscript.

\section{FUNDING}

The research reported in this article was supported by the National Institute of Allergy and Infectious Diseases of the National Institutes of Health under award number R01 AI056021. The content of this article is solely the responsibility of the authors and does not necessarily represent the official views of the National Institutes of Health.

\section{ACKNOWLEDGMENTS}

The authors thank members of the Sonenshein and Belitsky's laboratories for helpful suggestions and discussions during the course of this study.

\section{SUPPLEMENTARY MATERIAL}

The Supplementary Material for this article can be found online at: http://journal.frontiersin.org/article/10.3389/fmicb. 2017.01148/full\#supplementary-material

Chen, S., Zhang, A., Blyn, L. B., and Storz, G. (2004). MicC, a second smallRNA regulator of Omp protein expression in Escherichia coli. J. Bacteriol. 186, 6689-6697. doi: 10.1128/JB.186.20.6689-6697.2004

Chopra, I., and Eccles, S. J. (1978). Diffusion of tetracycline across the outer membrane of Escherichia coli K-12: involvement of protein Ia. Biochem. Biophys. Res. Commun. 83, 550-557. doi: 10.1016/0006-291X(78)91025-2

Cohen, S. P., McMurry, L. M., Hooper, D. C., Wolfson, J. S., and Levy, S. B. (1989). Cross-resistance to fluoroquinolones in multiple-antibiotic-resistant (Mar) Escherichia coli selected by tetracycline or chloramphenicol: decreased drug accumulation associated with membrane changes in addition to OmpF reduction. Antimicrob. Agents Chemother. 33, 1318-1325. doi: 10.1128/AAC. 33.8.1318

Cowan, S. W., Garavito, R. M., Jansonius, J. N., Jenkins, J. A., Karlsson, R., Konig, N., et al. (1995). The structure of Ompf porin in a tetragonal crystal form. Structure 3, 1041-1050. doi: 10.1016/S0969-2126(01)00240-4

Datsenko, K. A., and Wanner, B. L. (2000). One-step inactivation of chromosomal genes in Escherichia coli K-12 using PCR products. Proc. Natl. Acad. Sci. U.S.A. 97, 6640-6645. doi: 10.1073/pnas.120163297

Duval, V., Nicoloff, H., and Levy, S. B. (2009). Combined inactivation of lon and $y c g E$ decreases multidrug susceptibility by reducing the amount of OmpF 
porin in Escherichia coli. Antimicrob. Agents Chemother. 53, 4944-4948. doi: 10.1128/AAC.00787-09

Egger, L. A., and Inouye, M. (1997). Purification and characterization of the periplasmic domain of EnvZ osmosensor in Escherichia coli. Biochem. Biophys. Res. Commun. 231, 68-72. doi: 10.1006/bbrc.1996.6007

Forst, S., and Inouye, M. (1988). Environmentally regulated gene expression for membrane proteins in Escherichia coli. Annu. Rev. Cell Biol. 4, 21-42. doi: 10.1146/annurev.cb.04.110188.000321

Galdiero, S., Falanga, A., Cantisani, M., Tarallo, R., Della Pepa, M. E., D'Oriano, V., et al. (2012). Microbe-host interactions: structure and role of Gram-negative bacterial porins. Curr. Protein Pept. Sci. 13, 843-854. doi: $10.2174 / 138920312804871120$

Gogol, E. B., Rhodius, V. A., Papenfort, K., Vogel, J., and Gross, C. A. (2011). Small RNAs endow a transcriptional activator with essential repressor functions for single-tier control of a global stress regulon. Proc. Natl. Acad. Sci. U.S.A. 108, 12875-12880. doi: 10.1073/pnas.1109379108

Griffith, K. L., Shah, I. M., and Wolf, R. E. (2004). Proteolytic degradation of Escherichia coli transcription activators SoxS and MarA as the mechanism for reversing the induction of the superoxide (SoxRS) and multiple antibiotic resistance (Mar) regulons. Mol. Microbiol. 51, 1801-1816. doi: 10.1046/j.13652958.2003.03952.x

Hasegawa, K., Masuda, S., and Ono, T.-A. (2006). Light induced structural changes of a full-length protein and its BLUF domain in $\mathrm{YcgF}(\mathrm{Blrp})$, a blue-light sensing protein that uses FAD (BLUF). Biochemistry 45, 3785-3793. doi: 10.1021/ bi051820x

Igo, M. M., Ninfa, A. J., and Silhavy, T. J. (1989). A bacterial environmental sensor that functions as a protein kinase and stimulates transcriptional activation. Genes Dev. 3, 598-605. doi: 10.1101/gad.3.5.598

Jackson, M. W., Silva-Herzog, E., and Plano, G. V. (2004). The ATP-dependent ClpXP and Lon proteases regulate expression of the Yersinia pestis type III secretion system via regulated proteolysis of YmoA, a small histone-like protein. Mol. Microbiol. 54, 1364-1378. doi: 10.1111/j.1365-2958.2004.04353.x

Lee, J., Page, R., García-Contreras, R., Palermino, J.-M., Zhang, X.-S., Doshi, O., et al. (2007). Structure and function of the Escherichia coli protein YmgB: a protein critical for biofilm formation and acid-resistance. J. Mol. Biol. 373, 11-26. doi: 10.1016/j.jmb.2007.07.037

Mayer, M. P. (1995). A new set of useful cloning and expression vectors derived from pBlueScript. Gene 163, 41-46. doi: 10.1016/0378-1119(95)00389-N

Miller, J. (1972). Experiments in Molecular Genetics. Cold Spring Harbor, NY: Cold Spring Harbor Laboratory Press.

Mizuno, T., Chou, M. Y., and Inouye, M. (1984). A unique mechanism regulating gene expression: translational inhibition by a complementary RNA transcript (micRNA). Proc. Natl. Acad. Sci. U.S.A. 81, 1966-1970. doi: 10.1073/pnas.81.7. 1966

Mizuno, T., and Mizushima, S. (1990). Signal transduction and gene regulation through the phosphorylation of two regulatory components: the molecular basis for the osmotic regulation of the porin genes. Mol. Microbiol. 4, 1077-1082. doi: 10.1111/j.1365-2958.1990.tb00681.x

Mizusawa, S., and Gottesman, S. (1983). Protein degradation in Escherichia coli: the lon gene controls the stability of SulA protein. Proc. Natl. Acad. Sci. U.S.A. 80, 358-362. doi: 10.1073/pnas.80.2.358

Mortimer, P. G., and Piddock, L. J. (1993). The accumulation of five antibacterial agents in porin-deficient mutants of Escherichia coli. J. Antimicrob. Chemother. 32, 195-213. doi: 10.1093/jac/32.2.195

Nakasone, Y., Ono, T.-A., Ishii, A., Masuda, S., and Terazima, M. (2010). Temperature-sensitive reaction of a photosensor protein YcgF: possibility of a role of temperature sensor. Biochemistry 49, 2288-2296. doi: 10.1021/bi902121z

Nikaido, H. (1994). Porins and specific diffusion channels in bacterial outer membranes. J. Biol. Chem. 269, 3905-3908. doi: 10.1111/j.1365-2958.1992. tb01487.x

Nikaido, H. (2003). Molecular basis of bacterial outer membrane permeability revisited. Microbiol. Mol. Biol. Rev. 67, 593-656. doi: 10.1128/MMBR.67.4.593656.2003
Oethinger, M., Kern, W. V., Goldman, J. D., and Levy, S. B. (1998). Association of organic solvent tolerance and fluoroquinolone resistance in clinical isolates of Escherichia coli. J. Antimicrob. Chemother. 41, 111-114. doi: 10.1093/jac/41. 1.111

Pagès, J.-M., James, C. E., and Winterhalter, M. (2008). The porin and the permeating antibiotic: a selective diffusion barrier in Gramnegative bacteria. Nat. Rev. Microbiol. 6, 893-903. doi: 10.1038/nrmicro 1994

Pfaffl, M. W. (2001). A new mathematical model for relative quantification in real-time RT-PCR. Nucleic Acids Res. 29:e45. doi: 10.1093/nar/29.9.e45

Powell, B. S., Rivas, M. P., Court, D. L., Nakamura, Y., and Turnbough, C. L. (1994). Rapid confirmation of single copy lambda prophage integration by PCR. Nucleic Acids Res. 22, 5765-5766. doi: 10.1093/nar/22.25. 5765

Pratt, L. A., Hsing, W., Gibson, K. E., and Silhavy, T. J. (1996). From acids to osmZ: multiple factors influence synthesis of the $\mathrm{OmpF}$ and $\mathrm{OmpC}$ porins in Escherichia coli. Mol. Microbiol. 20, 911-917. doi: 10.1111/j.1365-2958.1996. tb02532.x

Silhavy, T. J., Berman, M. L., Enquist, L. W., and Laboratory, C. S. H. (1984). Experiments with Gene Fusions. Cold Spring Harbor, NY: Cold Spring Harbor Laboratory Press.

Simons, R. W., Houman, F., and Kleckner, N. (1987). Improved single and multicopy lac-based cloning vectors for protein and operon fusions. Gene 53, 85-96. doi: 10.1016/0378-1119(87)90095-3

Sugawara, E., and Nikaido, H. (1994). OmpA protein of Escherichia coli outer membrane occurs in open and closed channel forms. J. Biol. Chem. 269, 17981-17987.

Torres-Cabassa, A. S., and Gottesman, S. (1987). Capsule synthesis in Escherichia coli K-12 is regulated by proteolysis. J. Bacteriol. 169, 981-989. doi: 10.1128/jb. 169.3.981-989.1987

Tschowri, N., Busse, S., and Hengge, R. (2009). The BLUF-EAL protein YcgF acts as a direct anti-repressor in a blue-light response of Escherichia coli. Genes Dev. 23, 522-534. doi: 10.1101/gad.499409

Tschowri, N., Lindenberg, S., and Hengge, R. (2012). Molecular function and potential evolution of the biofilm-modulating blue light-signalling pathway of Escherichia coli. Mol. Microbiol. 85, 893-906. doi: 10.1111/j.1365-2958.2012. 08147.x

Tsilibaris, V., Maenhaut-Michel, G., and Van Melderen, L. (2006). Biological roles of the Lon ATP-dependent protease. Res. Microbiol. 157, 701-713. doi: 10.1016/ j.resmic.2006.05.004

Van Melderen, L., and Aertsen, A. (2009). Regulation and quality control by Londependent proteolysis. Res. Microbiol. 160, 645-651. doi: 10.1016/j.resmic.2009. 08.021

Vogel, J., and Papenfort, K. (2006). Small non-coding RNAs and the bacterial outer membrane. Curr. Opin. Microbiol. 9, 605-611. doi: 10.1016/j.mib.2006. 10.006

Yoshida, T., Qin, L., Egger, L. A., and Inouye, M. (2006). Transcription regulation of $o m p F$ and $o m p C$ by a single transcription factor. OmpR. J. Biol. Chem. 281, 17114-17123. doi: 10.1074/jbc.M602112200

Yoshimura, F., and Nikaido, H. (1985). Diffusion of beta-lactam antibiotics through the porin channels of Escherichia coli K-12. Antimicrob. Agents Chemother. 27, 84-92. oi: 10.1128/AAC.27.1.84

Conflict of Interest Statement: The authors declare that the research was conducted in the absence of any commercial or financial relationships that could be construed as a potential conflict of interest.

Copyright (c) 2017 Duval, Foster, Brewster and Levy. This is an open-access article distributed under the terms of the Creative Commons Attribution License (CC BY). The use, distribution or reproduction in other forums is permitted, provided the original author(s) or licensor are credited and that the original publication in this journal is cited, in accordance with accepted academic practice. No use, distribution or reproduction is permitted which does not comply with these terms. 